This item was submitted to Loughborough's Research Repository by the author.

Items in Figshare are protected by copyright, with all rights reserved, unless otherwise indicated.

\title{
Towards an economic approach to crime and prevention
}

PLEASE CITE THE PUBLISHED VERSION

PUBLISHER

(C) Macmillan

LICENCE

CC BY-NC-ND 4.0

\section{REPOSITORY RECORD}

Farrell, Graham, Sharon Chamard, Ken Clark, and Ken Pease. 2019. "Towards an Economic Approach to Crime and Prevention". figshare. https://hdl.handle.net/2134/928. 


\section{Towards an Economic Approach to Crime and Prevention}

Graham Farrell, Sharon Chamard, Ken Clark and Ken Pease

\section{Introduction}

When deciding to commit an offence, offenders take into account different factors. The key factors or variables in the economic model developed in this chapter are time and effort, risk, rewards, and available excuses as perceived by the offender. This is in keeping with the rational choice model of criminal decision-making (Cornish and Clarke, 1986, 1987) which is situated within the framework of situational crime prevention (see Clarke and Homel, 1997). The criminological theory is not reviewed at length, since the focus is upon transforming it into an economic framework. The principal influence in the criminological literature addressing crime and victimisation in an economic-type framework is van Dijk's (1992) macroeconomic model of the interaction between the rational choices of offenders and victims. This chapter takes a more micro-level approach, and shows how the model applies to the prevention of repeat victimisation. The contribution of Field and Hope's (1989) pioneering effort should also be acknowledged. It is intended that the present work should prove entirely compatible with these models.

Section II outlines the model of offender decision-making. Section III discusses how crime prevention works, that is, how the variables of time and effort, risk, rewards, and the removal of excuses, produce variations in the levels of crime. Section IV examines repeat victimisation and discusses the role of uncertainty in offender decision-making, and Section $\mathrm{V}$ discusses the possibilities for further research and development of the model.

The purpose of this chapter is not to develop criminological or crime prevention theory. Neither does it seek to advance the framework of economic analysis. This has been well developed since the time of Becker (1968). Our main aim is to begin to integrate the two; we contend that this synergy is the contribution. Specifically, the formal economic framework 
allows one to view clearly how offending decisions are made, how such decisions result in the same targets being repeatedly victimised, and how crime prevention interventions can reduce offending.

\section{The Model}

It is assumed that people are utility maximisers. People decide to undertake an activity, including the commission of a crime, if one essential criterion is met. An activity will be performed if the perceived or expected potential net benefits from time spent in that activity outweigh the expected net benefit from time spent in any of the perceived available alternatives. In the same set of circumstances, different people will make different decisions depending upon a multitude of factors such as attributes, skills and experience. The decision to offend is not unlike an economic labour supply problem involving a time-allocation decision. Is it rational to spend time committing this offence rather than doing something else?

A brief note is necessary here on the notion of limited rationality, or what economists call 'bounded' rationality. Clearly, the decision made by an offender is not always correct. A wrong decision can be made, but it was the perceived optimal decision at that time and in those circumstances, from the viewpoint of the offender. Also, 'rational' decision-making does not refer solely to hardened offenders seeking suitable targets. Even a normally law-abiding person may break the law if the benefits of committing the crime are perceived to outweigh the benefits of not committing the crime.

A person's overall utility is derived from the time spent offending and time spent in other activities. Hence,

$$
U=U\left(t_{\mathrm{L}}, t_{\mathrm{C}}\right)
$$

where $U$ is utility, $t_{\mathrm{L}}$ is time spent in legitimate activity (work and leisure), and $t_{\mathrm{C}}$ is time spent on criminal activity. Note that $t_{\mathrm{C}}+t_{\mathrm{L}}=T$ is the total time available for allocation. In any given period, most people will probably spend all of their time on legitimate activity and none on criminal activity. The amount of time spent on criminal activities will vary with the particular characteristics and experiences of the person as well as circumstances. From a person's particular set of physical and mental attributes, skills and experience, is derived their particular preference curve for committing a particular criminal act.

The relationship between the economic concept of utility and the variables mentioned in the offender decision-making process is relatively 
straightforward. The individual's decision is based on whether the additional benefit of spending an extra unit of time in criminal activity is outweighed by the cost. This additional benefit is the marginal utility of criminal activity and is related to the four factors of the situational crime prevention approach. These are (1) expected cost due to the perceived time and effort spent on offending, (2) expected cost due to risk, (3) the expected psychological cost of guilt and shame (when excuses are absent), and (4) the expected benefit (whether monetary or psychological) of the rewards. Rewards are the only benefit perceived by the offender, and for a crime to take place they must be perceived to outweigh all of the costs. The marginal utility of criminal activity is expressed as a function of time and effort (e), risks $(k)$, the absence of excuses $(G)$, and rewards $(R)$.

$$
U_{\mathrm{C}}^{\prime}(e, k, G, R)
$$

As effort or risk increases, or as rewards or the level of available excuses decreases, the marginal utility of crime decreases. From the perspective of most people in most instances, the actual or perceived costs will far outweigh the rewards, and so they do not commit crime.

If an individual believes the expected returns from spending time committing crime are greater than those expected from non-criminal activity, then more time will be allocated to criminal activity. It can be safely assumed that at some point the rewards per minute of time allocated to offending will begin to diminish. The optimal time-allocation point is reached when extra time spent offending would cost more than not offending. The amount of time spent offending is derived when the marginal utility of crime, $U_{C}^{\prime}$, is equal to the marginal utility of noncriminal activity, $U_{\mathrm{L}}^{\prime}$, so that

$$
U_{\mathrm{C}}^{\prime}=U_{\mathrm{L}}^{\prime}
$$

The intersection of the marginal utility curves of time spent offending $\left(U^{\prime} \mathrm{C}\right)$ and time spent in non-offending activity $\left(U_{L}^{\prime}\right)$ is shown as Fig. 5.1a. Total time is shown on the horizontal axis, and runs from zero to the maximum, $T$. This total is broken down into two components: time spent on crime, which runs between zero and $t_{C}{ }^{*}$, and time spent on noncriminal activity, which is measured by the distance between $t_{C}^{*}$ and $T$.

Different people have different sets of preferences, which means they have different marginal utility curves for crime. For example, even if some people are presented with a criminal opportunity, they prefer not to take it. This is because they do not perceive a net benefit when factors such as guilt and shame are incorporated. Such a situation is shown in Fig. $5.1 \mathrm{~b}$ as the curve $U_{\mathrm{C} 2}^{\prime}$ which always intersects $U_{\mathrm{L}}^{\gamma}$ at a point where zero time is 

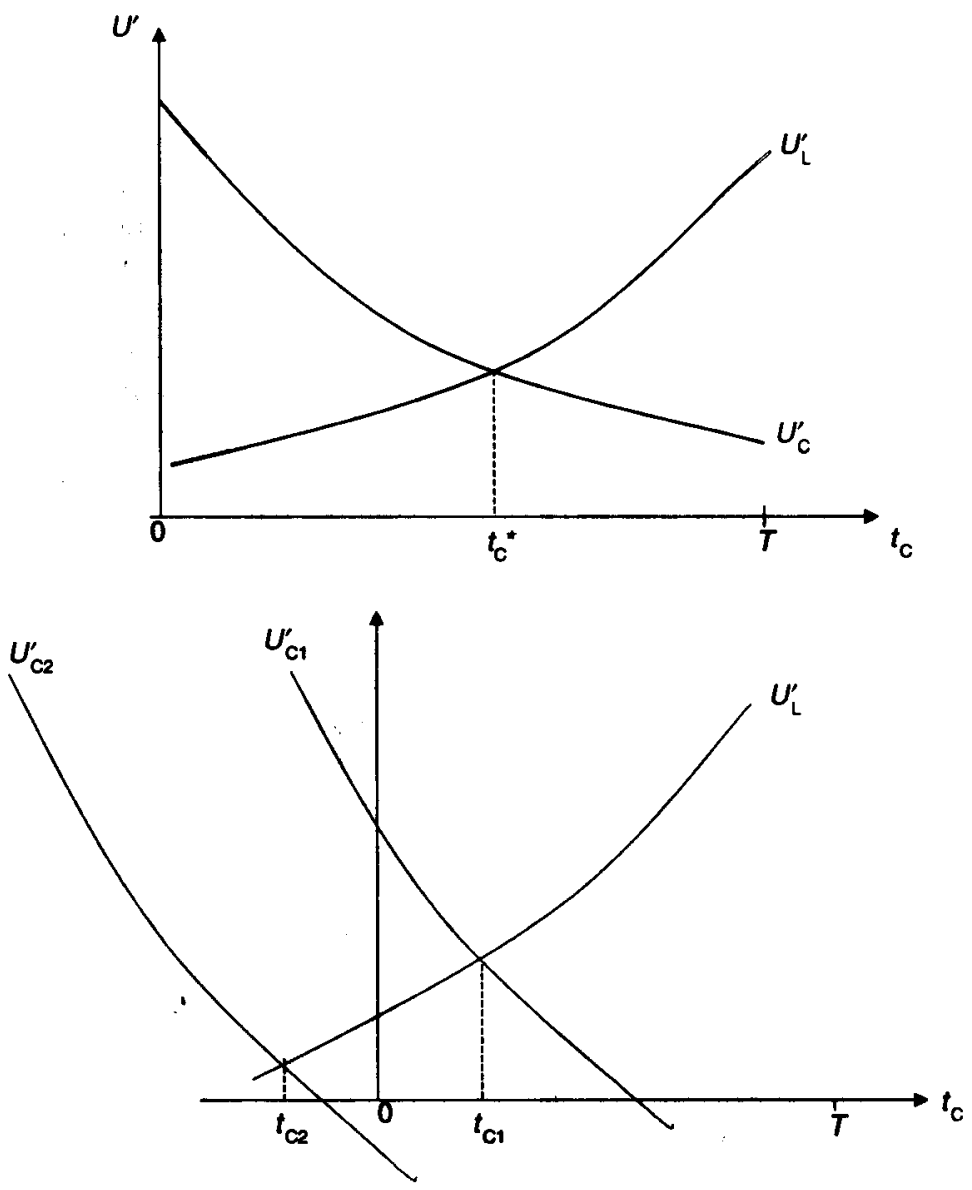

Figure 5.1 (a) Allocating time to crime: the marginal utility curves of time spent offending and time spent not offending; (b) a preference for crime? Different marginal utility curves results in offenders and non-offenders

allocated to crime. This contrasts with the person with a set of preferences that result in the marginal utility of crime curve of $U_{\mathrm{C} 1}^{\prime}$. This intersects with the marginal utility of non-criminal activity curve, $U_{\mathrm{L}}$, at a point where the amount of time between $T$ and $t_{\mathrm{C} 1}$ is allocated to criminal activity.

The amount of time a person allocates to commit crime will vary greatly with the crime type, circumstances, and the particular person. Many 
variables influence the relationship between time and crime. Different crimes take different amounts of time to commit, with wide variation by location and circumstance, people and their abilities.

The next issue is the fact that time and effort are related. Other things being equal, making something harder to do (such as making crime harder to commit), requires more time. The model of crime as a function of time is already, in effect, a model of crime as a function of time and effort. More time is more effort, and vice-versa. This is important for what comes later since many crime prevention interventions make crime more difficult, requiring more effort. This translates into the model as requiring more time for the commission of the offence. Any variations on the assumption that time is effort, such as notions of a degree of exertion, can more readily be introduced at a later date once the basic model has been established.

Next comes the fact that time and risk are inherently related. Risk is, as with most economic models to date, a function of the risk of arrest, conviction and punishment, where risk is increased primarily by increasing the severity of punishment. In the present model, if it takes more time to commit a crime, then assuming risks are constant per unit of time, risks increase proportionately with time. For example, car steeringwheel locks prevent crime by deterrence since it takes more time and effort to remove the lock, during which time someone may observe the crime and mobilise a capable guardian. Hence the broader definition of risk, denoted by $K$, is a function of time and effort, $e$, and other risks, $k$

$$
K=K(e, k)
$$

While the basic model of crime and prevention is a model of risk, the determinants of risk are broader than commonly specified in most economic analyses of crime. Time and effort carry far more weight as components of risk. They are explicitly rather than implicitly incorporated, and play a fundamental role. In the following section, when the techniques of situational crime prevention are presented, the roles of the different components of risk should become clearer because different elements of risk may be manipulated via different crime prevention interventions.

In addition to the changed definition of risk, the present model emphasises both rewards and shame. These can be directly influenced by crime prevention policy, and are significant influences upon the decision to offend. In previous models they are typically viewed as fixed factors or givens rather than variables that can be manipulated. Again, the role of each of these concepts is explained more fully in the following section. They are mentioned here in order to help clarify how the present economic analysis is intended to be different from previous ones. 


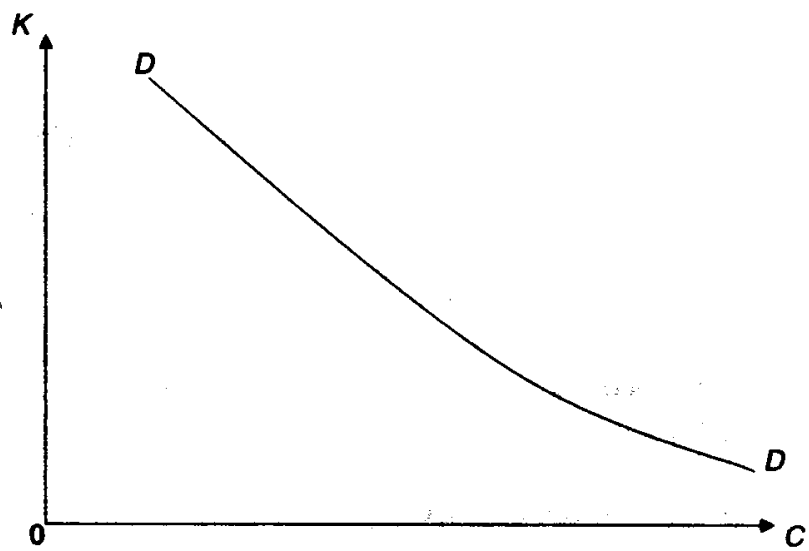

Figure 5.2 Risk and crime model

Drawing the elements together into Fig. 5.2, the quantity of crimes committed, $C$, is shown on the horizontal axis, with risk, $K$, on the vertical axis. Note that this single relationship now incorporates each of the individual components of equation (2). Risk, $K$, now incorporates time and effort $(t)$ as well as other risks $(r)$. Similarly, as will be shown below, the curve of the demand for offences by offenders, $D D$, can be altered by changes in perceived rewards or the level of available excuses. The risk crime relationship is assumed to be negative since, as it becomes more difficult to commit crime, the level of crime people are willing to commit will fall.

In what follows, the demand for offences by offenders is met by a supply of criminal opportunities. In keeping with van Dijk's terminology, victims (and potential victims) are the reluctant suppliers of criminal opportunities (van Dijk, 1992: 106). At any given point in time there is a given level of criminal opportunities in society. This may change over time as, say, the volume of consumer goods available for theft increases. Changes in the supply of criminal opportunities, perhaps the result of public policy or private interventions, play an important role in the present model. Although the supply of criminal opportunities was wonderfully developed in van Dijk's 1992 model, it is a factor that is often assumed to be constant in economic analyses of offender decisionmaking and crime policy. 


\section{How Does Crime Prevention Work?}

Crime prevention interventions increase the expected time and effort required to commit an offence, increase the expected risks of detection (and perhaps arrest, conviction and punishment), reduce the level of excuses that enable the commission of an offence, or reduce the expected potential rewards. This is the current model of situational crime prevention as proposed by Clarke (1997), based upon Clarke and Homel (1997). The table of 16 techniques is reproduced as Table 5.1, and provides concrete examples of prevention techniques, giving a real-world backdrop for the present chapter.

\section{A Increasing Expected Time and Effort}

As detailed in the previous section, increasing the time and effort required to commit an offence will result in an increased risk of detection. Detection involves a subsequent risk of apprehension and punishment, whether formally or informally meted out. Table 5.1 shows specific examples of how time and effort can be increased. The most popular example is target hardening, although the spectrum of possibilities is wide.

The previous section discussed why effort is time, and time is risk. Making a crime harder to commit means an offender must take more time (ceteris paribus) to commit it, resulting in more risk of detection. This may result in the offender being deterred. In the model, at any given level of risk, an increase in the time and effort required to commit an offence results in a reduction in the supply of criminal opportunities. While the demand for offences, shown as $D_{1} D_{1}$ in Fig. 5.3, remains the same, the supply of criminal opportunities curve shifts to the left, representing a reduction in supply. The increase in risk from $p_{1}$ to $p_{2}$ produces a decrease in offending from $c_{1}$ to $c_{2}$.

\section{B Increasing Expected Risks of Detection}

Increased risk of detection during the commission of a criminal act could result in a range of outcomes. Conceivably, a person detecting the offence may take no action if that person is a disinterested passer-by, someone who 'does not want to get involved', or someone incapable of taking action against the offender. Detection in this model therefore assumes detection by a capable guardian. This can result in a range of formal or informal outcomes, with the risk of arrest, conviction and punishment at the more formal end of the spectrum. The primary way risk is manipulated in the present model (excluding time and effort outlined above), is not via 
Economic Approach to Crime and Prevention 129

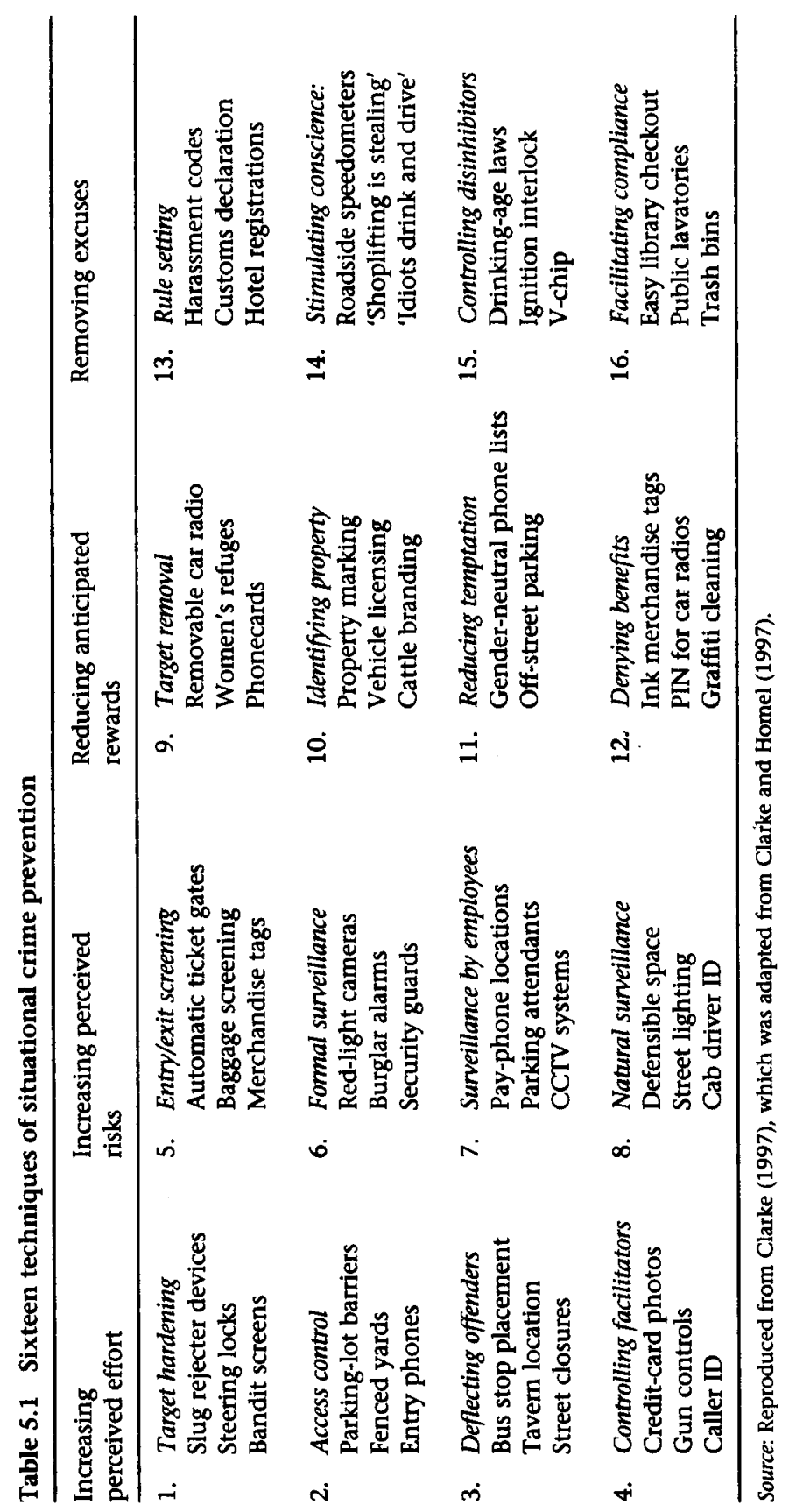


increased punishment as with many economic analyses, but via increased risk of detection. For present purposes the level of punishment is an assumed constant that is outside the scope of influence of most people or businesses. On the other hand, increasing risks of detection is increasingly seen as a far more variable private and public policy crime prevention instrument than previously envisaged. The potential for manipulating indirect risks of being observed, by passers-by, other citizens, colleagues or persons working in an area who may serve as capable guardians, is gaining increasing attention in criminology. Such risks are increased primarily by activities that are not related to the police but threaten the mobilisation of the police or private security. In practice, the threat of detection often results in crime being deterred because the criminal opportunity has effectively been removed.

In terms of the model, increasing detection risks due to exit screening, formal, informal or natural surveillance (see Table 5.1), operates in a similar manner to increasing time and effort. Increased risk of detection produces a reduction (a leftward shift) in the supply of criminal opportunities, from $S_{1} S_{1}$ to $S_{2} S_{2}$ in Fig. 5.3, with risk increasing from $p_{1}$ to $p_{2}$, leading to a fall in the volume of crime committed from $c_{1}$ to $c_{2}$.

Clearly, there is a connection between increasing the level of expected risks of detection and increasing the level of expected time and effort required. Overcoming increased risks of detection can involve more time and effort. While they are portrayed as operating via the same risk

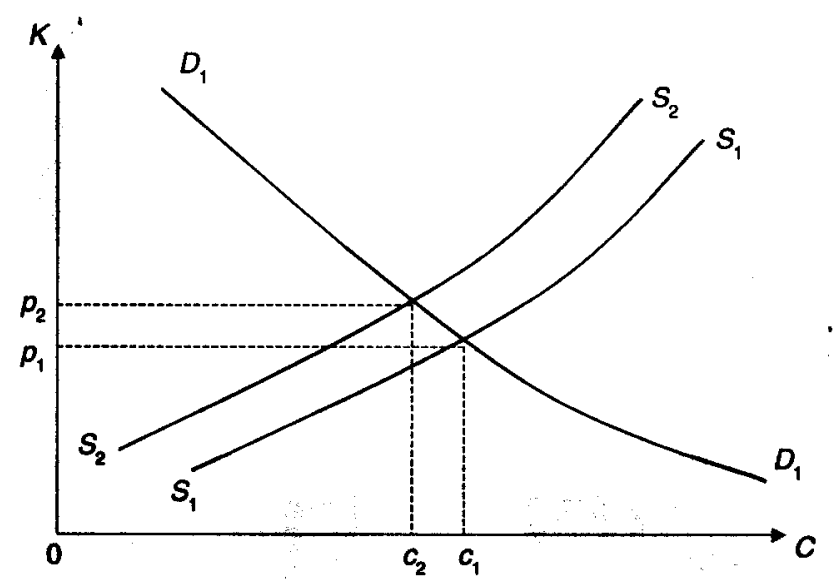

Figure 5.3 Increasing (time and effort and) risks of detection reduces criminal opportunities 
mechanism in the model, in practice these interventions can vary greatly in nature, as shown in Table 5.1. Both serve to reduce the supply of criminal opportunities, but how this happens in the real world varies greatly.

It may appear that the present model loses details by integrating time and effort plus other risks into a single 'risk of detection' variable. However, the model helps demonstrate how the different techniques reduce crime by shifting the supply of criminal opportunities. The significance of this will become more evident as the operational mechanisms for changed rewards or excuses are described.

\section{Reducing Expected Rewards}

If there is a reduction in the expected rewards to the commission of a crime then, at a given level of detection risk and criminal opportunities, fewer offenders will choose to commit the crime. At the extreme, removing the rewards will result in none of this type of crime being committed. Such changes are rare but might be said to have largely occurred in relation to thefts of work animals. When many work animals became outmoded due to automotive transportation, their re-sale value and hence profitability dropped, so that the market for theft of work animals diminished. A more modern example is the removal of subway graffiti in New York. Daily cleaning of subway cars meant that graffiti artists could not see their graffiti around the city. This removed the incentive or reward from the activity, and ultimately resulted in a large decline in graffiti (Sloan-Howitt and Kelling, 1997).

An actual or expected reduction in rewards leads to a drop in the perceived utility that an offender will derive from a crime. Looking back to Fig. 5.1b, a reduced reward might shift the preferences of an offender from curve $U_{C 1}^{\prime}$ to $U_{C 2}^{\prime}$ causing the offender to no longer wish to commit that offence. In the aggregate this lower level of willingness to commit a crime at a given level of risk and criminal opportunity manifests itself as a shift in the demand for offences. In Fig. 5.4 the original demand for offences by offenders is shown by $D_{1} D_{1}$, producing a level of crime $c_{1}$ at risk level $p_{1}$. With a reduction in rewards of a given offence, the supply of criminal opportunities does not change; instead the demand for offences shifts from $D_{1} D_{1}$ to $D_{2} D_{2}$. This produces a reduction in the overall level of offences from $c_{1}$ to $c_{2}$. For the lower level of rewards now available, offenders will be less willing to incur risk (time and effort and other risk of detection), so that the market level of risk they will incur at that level of criminal opportunities drops from $p_{1}$ to $p_{2}$. 


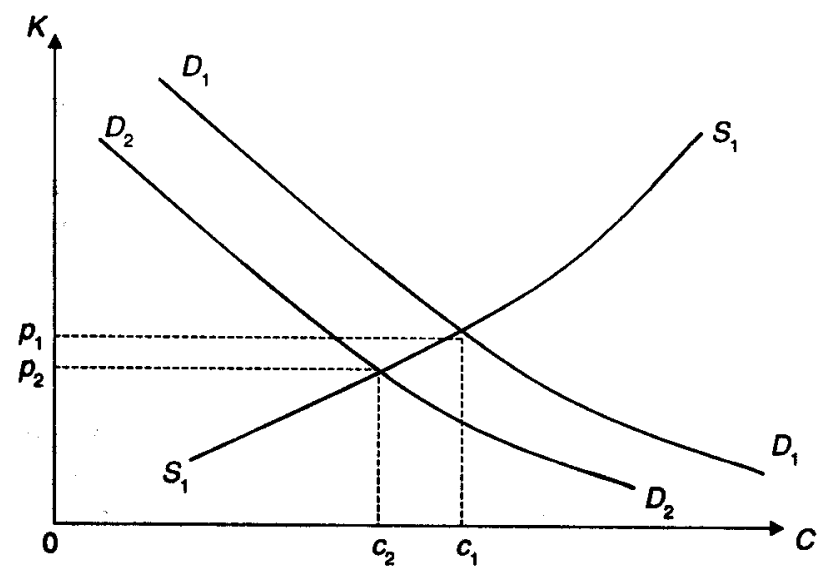

Figure 5.4 Reducing rewards or removing excuses reduces the demand for offences by offenders

\section{Removing Excuses}

Removing excuses is the most recent arm of situational crime prevention techniques. Setting rules, such as customs declarations that remove any excuse for a failure to declare taxable goods, removes the possibility of excusing oneself due to ignorance. Other simple measures, such as rubbish bins that facilitate disposal without littering, are among the range of tactics.shown in Table 5.1.

In terms of the model, removing excuses operates via a mechanism similar to a reduction in rewards. Due to the lower level of excuses available, the utility of the offender has been reduced for the same level of risks and rewards. As illustrated in Figure 5.4, this shift in preferences results in an inward shift in the demand for offences curve from $D_{1} D_{1}$ to $D_{2} D_{2}$, with a drop in the level of offences committed from $c_{1}$ to $c_{2}$.

\section{E Combined Techniques}

Four separate mechanisms for preventing crime have been presented in terms of the economic model. Clearly they need not, and do not, work in isolation. What if, for instance, an office manager makes computers harder for thieves to remove by fastening them to a surface, increases the formal surveillance of the office by locating secretarial staff at the entrance to meet newcomers, and also property marks the computers to reduce their re-sale value? The first aspect would increase the time and effort required to remove a computer (increasing risk); the second aspect would 
increase risks of detection (probably acting as a deterrent); and the third would reduce the rewards of stealing the computers since propertymarked products are difficult to fence. The anticipated net reduction in crime would be the result of shifts in both the supply of criminal opportunities and the demand for crime by offenders.

\section{Repeat Victimisation and Certainty}

Once victimised, the same targets are more likely to be repeatedly victimised. There is an increasing amount of research examining how, where, why and when this occurs, and developing the implications for crime prevention and other areas of public policy (Pease, 1998). How would repeat victimisation be the result of rational offender decisionmaking in the context of the present model? Where the same offender is involved, the answer may be that repeat victimisation is rational since the level of uncertainty involved has been reduced.

Offending decisions take place under uncertainty. The offender seeks to minimise uncertainty by developing rational expectations of the costs and benefits related to an offence. Where there is uncertainty, at least one of the variables (risk, rewards, the level of excuses) is imperfectly known. That is, the actual costs and benefits are unknown quantities. Rather, the offender has estimates of what is expected. These estimates will cover a range of possible values, the range being narrower where uncertainty is least. Where there is great uncertainty relating to risk or rewards, for example the possibility of the costs outweighing the benefits, then ceteris paribus, the offender may be less likely to commit this offence. The levels of costs and benefits can be envisaged as estimated within parameters. Offenders may collect information to try to narrow the parameters by improving their knowledge of likely risks and rewards, such as when a burglar 'cases' a property. After committing an offence, an offender has far more accurate knowledge of the costs and benefits of that particular crime. When considering further offending, if an offender assumes that little has changed in the interim to make the target less attractive (which could be an incorrect assumption), there is less uncertainty involved in victimising that target again. The costs and benefits are known with greater accuracy unless the situation relating to the target has been altered. Hence, in some instances, repeatedly victimising the same target is a rational choice since it is known to be a more attractive prospect than the available alternatives.

In Figure 5.5, the offender does not know the exact risk that would be involved in committing a crime. It could be at the level $p_{1}$ or at $p_{2}$, or somewhere in between. In the aggregate, the number of crimes 


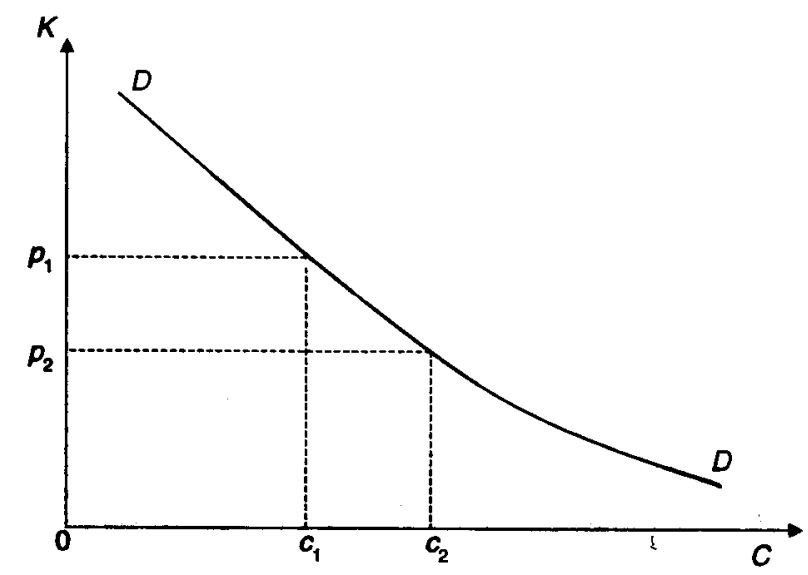

Figure 5.5 Repeat victimisation committed with reduced risk uncertainty

committed under such conditions might be about midway between $c_{1}$ and $c_{2}$. If, after committing the crime, an offender learns that the true level of risk is close to $p_{2}$, then, in the aggregate, the level of repeat victimisations committed will be close to $c_{2}$.

While this discussion of repeat victimization involved only uncertainty relating to risks, a similar uncertainty can exist in relation to rewards, or even the level of excuses. Since both operate via shifts in the demand curve, it is simpler for present purposes to talk of uncertainty relating to rewards. Fig. 5.6 shows offending under uncertainty in relation to both risks and rewards. Under uncertainty, offenders do not know if the level of risk is at $p_{1}, p_{2}$, or somewhere in between. Similarly, that offender does not know if the level of rewards would leave him/her on the demand curve $D_{1} D_{1}$ or $D_{2} D_{2}$ or somewhere in-between. Assuming a normal distribution of risk aversion, then the level of crime committed would be about midway between $c_{1}$ and $c_{2}$. If, on the other hand, offenders knew that the true level of risk was $p_{2}$ and that the true level of rewards would result in a demand $D_{1} D_{1}$, then the level of crimes committed would be far higher at $c_{2}$. Hence to keep crime at a minimum, creating the appearance of a greater than actual risk or lower than actual reward will result in a lower level of crime. Allowing offenders to estimate risks and rewards with certainty is a means to facilitate more accurate decision-making on their part. Note that in order to reduce or prevent crime, the role of uncertainty should be solely to make risks appear higher and rewards lower than in actuality. 


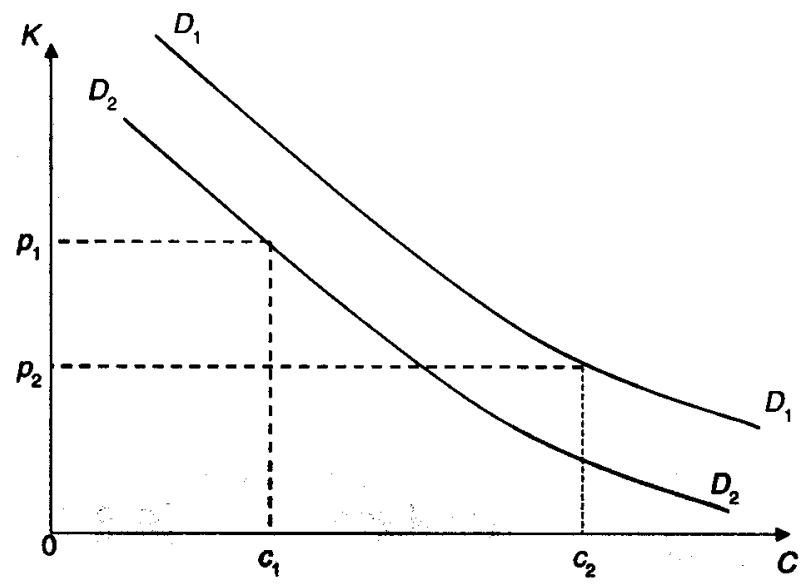

Figure 5.6 Offending under uncertainty of both risk and rewards

\section{Discussion and Concluding Remarks}

The model presented may provide a platform upon which a range of theories and empirical studies can be developed. The model can easily demonstrate how 'hardened' offenders with a steep demand curve may be less responsive to reductions in opportunity than more amateur and opportunistic offenders with less steep demand curves. It may prove possible to model how organised crime reacts to prevention, particularly for crimes with exceptionally high profits such as drug trafficking. Crime rate changes due to shifts in routine-activity-type variables, and the manner in which they influence crime, are relatively easily shown. For example, the supply of criminal opportunities increases if there is an increase in consumer goods available, increasing the number of criminal opportunities at any given level of risk and thereby expanding the market for crime (as in van Dijk's 1992 macro-model). The whole area of the elasticity of demand with respect to changes in supply for particular crime types, their variation across time and space, and notions of cross-crime type (product) switching may relate to aspects of crime deflection, displacement and prevention in ways that have not yet been explored. It may also be possible to determine when the slope of the demand curve changes, which corresponds with the point at which people's routine preventive precautions require additional expenditure so that they become more expensive 'special' precautions. Crime prevention resources 
might be allocated more efficiently at those times and to those places, in relation to those crime types and circumstances, where the elasticity of demand for crime is greatest.

In many of the instances discussed above, the formal economic model may provide a clear framework for analysis, with the aim of informing policy development, as well as the potential for the development of empirical studies. Although a model of crime and prevention may never be as influential as Becker's model of crime and punishment, it is not impossible that, with further development and research, it could be used to inform optimal policy-making in relation to public and private crime prevention policy, allocations and expenditures. For example, it should be possible to model how and why crime prevention should seek to maximise uncertainty on the part of offenders in order to reduce repeat victimisation. Similarly, integrating the different perspectives into a comprehensive criminal justice model within an economic framework could be a long-term goal from which fruitful insights can be gained.

If the present model of criminal decision-making appears both simple and somewhat similar to previous economic analyses of crime, then part of the aim of this chapter has been achieved. Neither the economic framework nor criminological theory presented is new. Putting the two explicitly together in this manner may be. In particular, the manner in which risk is constituted and influences the supply of criminal opportunities, and the roles of rewards and excuses, have significantly changed from economic models of crime that focused upon punishment. This is not to state that 'crime and punishment' models are incompatible with the present model. Rather, the present model places an emphasis ùpon different variables which are likely to suggest different policy implications. Although not formally mathematically proven in the way that Becker showed how punishment works, it is possible that formal mathematical development of the present analysis can be used to explore how prevention works. In time it could lead to analysis that derives optimal levels of prevention of different techniques and methods, and thus to recommendations for public and private policies against crime.

\section{References}

Becker, G. (1968) 'An Economic Approach to Crime and Punishment', Joumal of Political Economy, 76, pp. 169-217.

Clarke, R. V. and Homel, R. (1997) 'A Revised Classification of Situational Crime Prevention Techniques', in S. P. Lab (ed.), Crime Prevention at a Crossroads (Cincinnati, $\mathrm{OH}$ : Anderson) pp. 35-57. 
Clarke, R. V. (1997) 'Situational Crime Prevention', in R. V. Clarke (ed.), Situational Crime Prevention: Successful Case Studies, 2nd edn (Guilderland, NY: Harrow and Heston) pp. 1-18.

Cornish, D. and Clarke, R. V. (1985) 'Modelling Offenders' Decisions: a Framework for Research and Policy', in M. Tonry and N. Morris (eds), Crime and Justice: An Annual Review of Research, vol. 6 (Chicago, IL: University of Chicago Press), pp. 147-85.

-, - (1986) The Reasoning Criminal (New York: Springer-Verlag).

-, - (1987) 'Understanding Crime Displacement: an Application of Rational Choice Theory', Criminology, 25, pp. 933-47.

Field, S. and Hope, T. (1989) 'Economics and the Market in Crime Prevention', Research Bulletin 26, Home Office Research and Planning Unit, 40-4 (London: HMSO).

Pease, K. (1998) Repeat Victimisation: Taking Stock, Home Office Police Research Series Paper 90 (London: Home Office).

Sloan-Howitt, M. and Kelling, G. L. (1997) 'Subway Graffiti in New York: "Getting up" vs. "Meanin' it and Cleanin' it" ', in R. V. Clarke (ed.), Situational Crime Prevention: Successful Case Studies, 2nd edn (Harrow and Heston) pp. 242-9.

van Dijk, J. J. M. (1992) 'Understanding Crime Rates: On the Interactions Between Rational Choices of Victims and Offenders', British Joumal of Criminology, 34, pp. 105-21. 